\title{
PENERAPAN VIRTUAL LABORATORY UNTUK MEREDUKSI MISKONSEPSI MAHASISWA TENTANG FLUIDA
}

\section{Hamdani $^{1}$ \\ Dosen Pendidikan Fisika FKIP Universitas Tanjungpura Hamdani052185@gmail.com}

\begin{abstract}
Abstrak : Penelitian ini bertujuan mereduksi miskonsepsi mahasiswa tentang fluida menggunakan virtual laboratorium. Pengumpulan data menggunakan tes diagnostik berupa pilihan ganda dengan alasan terbuka pada satu kelas yang dipilih secara intact group. Hasil penelitian menunjukkan penerapan virtual laboratorium dapat mereduksi miskonsepsi tentang fluida yang dialami mahasiswa.
\end{abstract}

Kata kunci: Virtual Laboratory, Miskonsepsi, Fluida

\begin{abstract}
Abstrak :This study aims to reduce pre-service physics teachers' misconceptions about fluid using virtual laboratory. To obtain data, diagnostic test (multiple choice) with opened-reasons was given to students that were selected by intact group. The result shows that virtual laboratory can reduce students' misconception.
\end{abstract}

Key words: virtual laboratory; misconceptions; fluid

\section{Pendahuluan}

Miskonsepsi merupakan salah satu faktor penyebab rendahnya hasil belajar. Menurut Suparno (2005) miskonsepsi terjadi pada semua jenjang pendidikan (Sekolah Dasar, Sekolah Menengah Pertama, Sekolah Menengah Atas dan Perguruan Tinggi). Mahasiswa di perguruan tinggi memungkinkan untuk mengalami miskonsepsi.

Hasil pra riset menunjukkan mahasiswa mengalami miskonsepsi tentang fluida. Bentuk miskonsepsi yang diungkap antara lain mahasiswa menganggap semakin laju alir fluida dalam pipa maka tekanannnya juga semakin besar; ada mahasiswa yang beranggapan untuk wadah yang berhubungan tekanan hidrostatis berbeda pada kedalaman yang sama (pada kedalaman yang sama, alas wadah yang kecil memiliki tekanan hidrostatis yang besar dibandingkan dengan alas wadah yang besar); mahasiswa menganggap massa jenis fluida

\footnotetext{
${ }^{1}$ Hamdani adalah Dosen Prodi Pendidikan FISIKA FKIP Untan
} 
tidak mempengaruhi tekanan hidrostatis; mahasiswa beranggapan ketika ada beban yang dicelupkan ke dalam wadah tekanan hidrostatisnya tetap.

Miskonsepsi sulit diubah dengan pengajaran yang biasa, beberapa metode pengajaran yang telah dilakukan untuk mengatasi miskonsepsi antara lain learning cycle, conceptual change theory, bridging analogies, micro computerbased laboratory experiences, disequilibrium techniques, inquiry approach yang dipasangkan dengan strategi substitusi konsep, demonstrasi, diskusi (Wenning, 2008), kegiatan laboratorium (McDermott dan Shaffer,1992) dan Teaching-With-Analogy (Dilber danDuzgun, 2008).

Pembelajaran yang berkembang saat ini salah satunya memanfaatkan virtual laboratory. Hasil penelitian menunjukkan kegiatan virtual lab lebih produktif dibandingkan dengan metode tradisional (Finkelstein, 2005; Zacharia dan Constantinou, 2008); membantu mahasiswa memahami mekanika kuantum yang bersifat abstrak (McKagan, 2008); simulasi virtual dapat meningkatkan pemahaman konsep dan meminimalkan miskonsepsi (Suhandi, 2008). Simulasi komputer dapat digunakan untuk menyediakan pembelajaran interaktif yang menghadirkan fenomena fisika, yang mungkin bertentangan dengan konsepsi peserta didik. Pengalaman ini dapat mendorong peserta didik memodifikasi konsepsi mereka yang keliru (Zacharia dan Anderson, dalam Richards, 2010)

Berdasarkan pemaparan di atas peneliti berupaya mereduksi miskonsepsi mahasiswa tentang fluida melalui penerapan virtual laboratory yang bersumber dari Physics Education Technology (PhET).

\section{Masalah}

Bagaimana perubahan jumlah miskonsepsi mahasiswa tentang fluida setelah pembelajaran yang menggunakan virtual laboratory?

\section{Metode Penelitian}

Desain penelitian yang digunakan dalam penelitian ini berupa "one-group pretest-postest design"dengan cara memberikan pretest kemudian memberikan perlakuan terhadap satu kelompok dan setalah perlakuan diberikan posttest. Penelitian ini dilakukan di salah satu universitas di Pontianak (Kalimantan Barat) pada mahasiswa calon guru fisika semester 3 tahun akademik 2014/2015. Populasi dalam penelitian ini adalah mahasiswa semester tiga yang mengambil mata kuliah mekanika. Populasi tersebut terdiri dari tiga kelas. Pemilihan sampel dilakukan dengan memilih seluruh siswa dalam satu kelas yang dipilih dengan teknik intact group. Alat pengumpul data yang digunakan berupa tes diagnostik berbentuk pilihan ganda dengan alasan terbuka tentang fluida. Tes terdiri dari 12 soal yang diujikan pada saat pretest dan posttest. 
Mahasiswa yang mengalami miskonsepsi diidentifikasi dari jawaban tes diagnostik yang berbentuk pilihan ganda dengan alasan terbuka. Mahasiswa tidak mengalami miskonsepsi jika pilihan jawaban dan alasan yang dikemukakan benar, selain itu mahasiswa dianggap mengalami miskonsepsi

Untuk menguji hipotesis virtual laboratory dapat mereduksi miskonsepsi, maka dilakukan uji McNemar. Uji ini dapat dipakai untuk mengetahui signifikansi perubahan dengan rancangan penelitian "before after" yang datanya berbentuk nominal atau diskrit (Sugiyono, 2009).

\section{Hasil Penelitian}

Secara deskriptif penurunan kuantitas miskonsepsi dilakukan dengan menghitung selisih rata-rata persentase miskonsepsi mahasiswa pada saat pretest dan posttest. Rata-rata persentase miskonsepsi mahasiswa pada saat pretest dan posttest disajikan dalam gambar 1 .

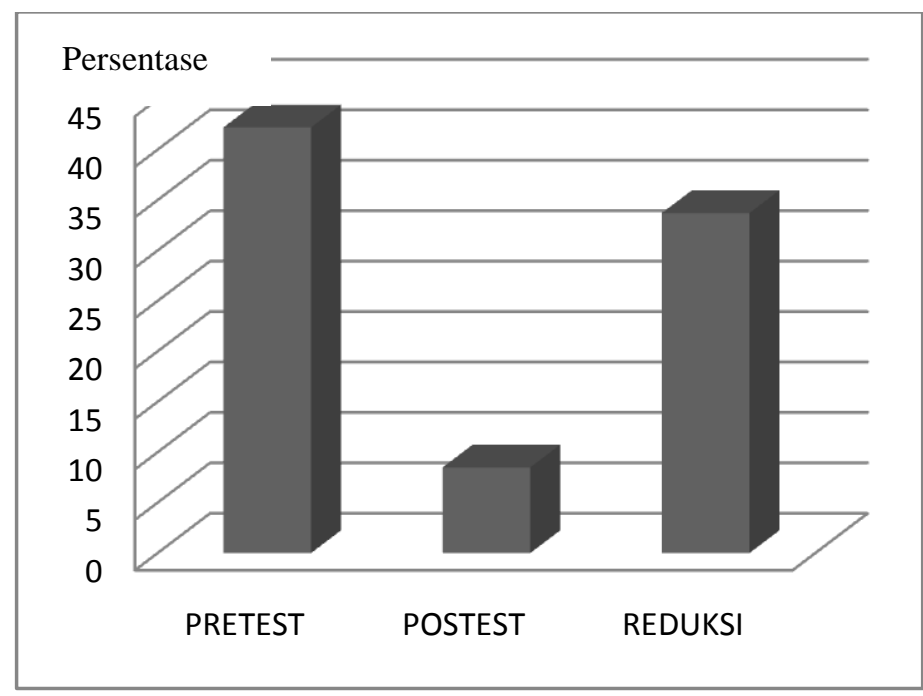

Gambar 1 Rata-rata persentase miskonsepsi mahasiswa sebelum dan setelah penerapan virtual laboratory.

Berdasarkan Gambar 1 secara umum setelah pembelajaran terjadi penurunan kuantitas miskonsepsi. Pada saat pretest rata-rata persentase yang mengalami miskonsepsi sebesar $42,20 \%$, sedangkan pada saat posttest rata-rata persentase yang mengalami miskonsepsi sebesar 8,49\%. Hasil ini menunjukkan terjadi reduksi miskonsepsi sebesar $33,71 \%$. 
Secara deskriptif penurunan miskonsepsi juga terjadi pada semua konsep. Rata-rata persentase miskonsepsi mahasiswa pada saat pretest dan posttest pada setiap konsep tentang fluida disajikan pada Gambar 2.

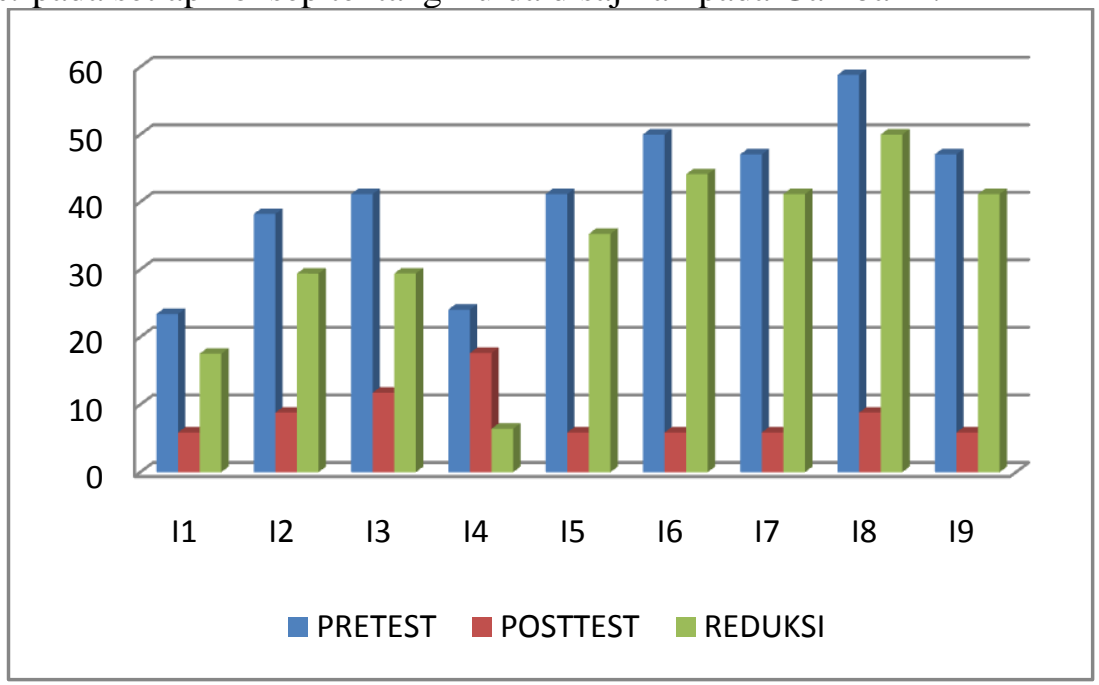

Gambar 2. Rata-rata persentase miskonsepsi mahasiswa tiap indikator soal Keterangan:

Konsep 1 (K1) : Hubungan kedalaman dengan tekanan hidrostatis Konsep 2 (K2) : Hubungan massa jenis dengan tekanan hidrostatis Konsep 3 (K3) : Hubungan tekanan hidrostatis di dua wadah yang berhubungan pada kedalaman yang sama

Konsep 4 (K4) : Pengaruh objek yang dimasukan ke dalam fluida terhadap tekanan hidrostatis pada fluida tersebut

Konsep 5 (K5) : Hubungan kecepatan alir fluida dengan luas penampang

Konsep 6 (K6) : Hubungan kecepatan alir fluida dengan tekanan

Konsep 7 (K7) : Hubungan jarak lintasan fluida yang keluar dari wadah dengan massa jenis fluida

Konsep 8 (K8) : Hubungan jarak lintasan fluida yang keluar dari wadah dengan ketinggian tower tempat wadah diletakan

Konsep 9 (K9) : Hubungan tinggi tower dengan tekanan hidrostatis

Berdasarkan Gambar 2 dapat diidentifikasi bahwa seluruh konsep yang diujikan pada konsep fluida mengalami miskonsepsi. Untuk setiap konsep dalam fluida rata-rata persentase miskonsepsi pada saat posttest lebih kecil dibandingkan dengan pretest. Hal ini menunjukan terjadi 
penurunan kuantitas miskonsepsi setelah virtual laboratory diterapkan. Reduksi miskonsepsi tertinggi terjadi pada konsep hubungan jarak lintasan fluida yang keluar dari wadah dengan ketinggian tower tempat wadah diletakkan (K8), sedangkan reduksi miskonsepsi terendah terjadi pada konsep pengaruh objek yang dimasukan ke dalam fluida terhadap tekanan hidrostatis pada fluida tersebut (K4).

Uji McNemar juga dilakukan pada tiap konsep tentang fluida untuk menentukan signifikansi perubahan miskonsepsinya. Hasil uji McNemar tiap konsep pada fluida disajikan pada Tabel 1 .

Tabel 1

Rekapitulasi uji McNemar tiap konsep pada fluida

\begin{tabular}{|c|c|c|c|c|c|c|c|}
\hline No & $\begin{array}{c}\text { Konsep } \\
\text { Fluida }\end{array}$ & $\begin{array}{c}\text { Nomor } \\
\text { Soal }\end{array}$ & $\mathrm{A}$ & $\mathrm{B}$ & $\mathrm{C}$ & $\mathrm{D}$ & $\chi^{2}$ \\
\hline 1 & K1 & 1 & 1 & 31 & 1 & 9 & 6,44 \\
\hline 2 & $\mathrm{~K} 2$ & 2 & 0 & 29 & 3 & 10 & 8,10 \\
\hline 3 & $\mathrm{~K} 3$ & 3 & 1 & 28 & 3 & 10 & 7,40 \\
\hline 4 & $\mathrm{~K} 4$ & $4,5,6,7$ & 3 & 129 & 3 & 33 & 28,48 \\
\hline 5 & K5 & 8 & 1 & 28 & 1 & 12 & 9,33 \\
\hline 6 & K6 & 9 & 0 & 25 & 2 & 15 & 13,06 \\
\hline 7 & K7 & 10 & 1 & 26 & 1 & 14 & 11,29 \\
\hline 8 & K8 & 11 & 0 & 22 & 3 & 17 & 15,06 \\
\hline 9 & K9 & 12 & 1 & 26 & 1 & 14 & 11,29 \\
\hline
\end{tabular}

Keterangan:

$\mathrm{A}=$ Mahasiswa yang paham konsep pada pretest, dan miskonsepsi pada posttest

$\mathrm{B}=$ Mahasiswa yang paham konsep pada pretest dan posttest

$\mathrm{C}=$ Mahasiswa yang miskonsepsi pada pretest dan posttest

$\mathrm{D}=$ Mahasiswa yang miskonsepsi pada pretest, dan paham konsep pada posttest

Berdasarkan hasil uji McNemar pada tabel 4.1 diperoleh untuk semua konsep fluida $x^{2}{ }_{\text {hitung }}$ lebih besar dari $x^{2}$ tabel $(3,84$ dengan taraf signifikansi 5\%) maka $\mathrm{H}_{\mathrm{a}}$ diterima. Hasil ini menunjukkan penerapan virtual laboratory secara signifikan dapat mereduksi miskonsepsi mahasiswa tiap konsep fluida.

\section{Pembahasan}

Secara keseluruhan berdasarkan hasil uji McNemar untuk semua butir

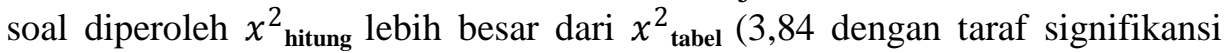
$5 \%$ ). Hasil ini menunjukkan penerapan virtual laboratory dapat mereduksi miskonsepsi mahasiswa. Melalui kegiatan virtual laboratory mahasiswa dapat 
memanipulasi data, mengumpulkan data, menganalisis data dan mengambil keputusan. Dalam simulasi mahasiswa menemukan data yang berbeda dengan yang mereka pikirkan (prediksi), maka mahasiswa akan mengalami konflik dalam pikirannya (konflik kognitif). Hasil simulasi yang bertentangan dengan konsepsi awal mahasiswa yang diulang berkali-kali akan menghasilkan perubahan konsepsi dalam dirinya (Suparno, 2005). Salah satu pendekatan pembelajaran yang dapat mengatasi miskonsepsi adalah pembelajaran yang melibatkan peran aktif peserta didik dalam pembelajaran (Tarakegn, 2009), hal ini dapat dilakukan melalaui kegitan virtual lab (Jimoyiannis dan Komis, 2000, Zacharia dan Anderson dalam Richards, 2010). Selain itu kegiatan virtual lab dapat digunakan untuk memperbaiki dan mengkonfrontasi miskonsepsi (Hewson, Tao, dalam Jimoyiannis dan Komis, 2000)

Berdasarkan hasil penelitian yang dilakukan tidak semua konsepsi mahasiswa yang keliru dapat diperbaiki. Salah satu faktor penyebab tidak semua miskonsepsi dapat diperbaiki karena pada saat kegiatan virtual lab interaksi dosen dengan mahasiswa dirasakan kurang. Interaksi yang kurang dikarenakan banyaknya jumlah kelompok yang harus diakomodasi, sehingga tidak semua kebutuhan mahasiswa terpenuhi. Hal ini sesuai dengan pernyataan Berg (1991) kunci untuk perbaikan konsepsi yang keliru adalah interaksi dengan peserta didik. Selain itu berdasarkan hasil observasi ada beberapa mahasiswa yang kurang berperan aktif dalam kelompoknya.

Reduksi miskonsepsi terendah terjadi pada konsep 4 (K4): Pengaruh objek yang dimasukan ke dalam fluida terhadap tekanan hidrostatis pada fluida tersebut sebesar 6,42 \%. Hal ini mungkin disebabkan karena soal yang digunakan pada konsep ini lebih banyak dibandingkan dengan soal yang digunakan pada konsep lain. Selain itu soal yang diujikan relatif lebih kompleks dibandingkan dengan soal yang lain khususnya tentang tekanan hidrostatis. Temuan ini didukung oleh Osborne dan Freyberg, gilbert dan Watss dalam Berg (1990) yang menyatakan soal-soal yang sederhana dapat dikerjakan, tetapi dengan soal yang relatif lebih sulit miskonsepsi muncul lagi.

Reduksi miskonsepsi tertinggi terjadi pada konsep 8 (hubungan jarak lintasan fluida yang keluar dari wadah dengan ketinggian tower tempat wadah diletakan). Tingginya reduksi miskonsepsi pada konsep ini dikarenakan pada virtual lab disajikan fenomena air yang keluar dari tangki yang ketinggiannya tower dapat dimanipulasi (diubah ketinggiannya). Melalui virtual lab mahasiswa dapat mengdidentifikasi hubungan jarak lintasan fluida yang keluar dari wadah dengan ketinggian tower tempat wadah diletakan dan membuat kesimpulan yang tepat. 


\section{Kesimpulan dan Saran}

Berdasarkan data hasil penelitian, pengolahan data, analisis data dan pembahasan data maka dapat disimpulkan penerapan virtual laboratory dapat mereduksi miskonsepsi tentang fluida yang dialami mahasiswa sebesar $33,71 \%$. Reduksi miskonsepsi tertinggi terjadi pada hubungan jarak lintasan fluida yang keluar dari wadah dengan ketinggian tower tempat wadah diletakkan sebesar 50,00\% dan reduksi miskonsepsi terendah terjadi pada konsep pengaruh objek yang dimasukan ke dalam fluida terhadap tekanan hidrostatis pada fluida tersebut sebesar $6,43 \%$. Uji McNemar menunjukkan penerapan virtual laboratory secara signifikan dapat mereduksi miskonsepsi mahasiswa tiap konsep fluida.

Beberapa saran yang dapat dipertimbangkan untuk mereduksi miskonsepsi yang dialami mahasiswa antara lain: tes diagnostik sebaiknya diberikan pada setetiap pertemuan, agar miskonsepsi yang masih bertahan dapat diidentifikasi dan diminimalisir, sehingga tidak menjadi penyebab miskonsepsi tentang konsep yang dipelajari pada pertemuan selanjutnya; jumlah soal pada tes diagnostik untuk setiap konsep sebaiknya disusun secara proporsional sehingga menghasilkan perbandingan reduksi miskonsepsi antar konsep yang lebih valid; kegiatan virtual laboratory sebaiknya dilakukan tutorial terlebih dahulu sebelum kegiatan praktikum dilakukan agar waktu yang digunakan lebih efektif; bagi penelitian selanjutnya dapat menggunakan kombinasi real laboratory dan virtual laboratory untuk mereduksi miskonsepsi.

\section{Referensi}

Berg, V. D. (1991). Miskonsepsi Fisika dan Remediasi. Salatiga: UKSW

Dilber, R. dan Duzgun, B. (2008). "Effectiveness of Analogy on Students' Success and Elimination of Misconceptions".Latin American Journal of Physics Education. 2, (3), 174-183

Finkelstein, N. D, et al (2005). "When Learning About the Real World is Better Done Virtually: A Study of Substituting Computer Simulations for laboratory Equipment". Physical Review Special Topics-Physics Education Research 1, 010103

Jimoyiannis, A danKomis, V. (2001). "Computer Silulations In Physics Teaching and Learning: A Case Study On Students' Understanding of

Trajectory Motion". Computers and Education. 36, 183-204

McDermott, L.C dan Shaffer, P.S, (1992). "Research As A Guide For Curriculum Development: An Example From Introductory Electricity. Part I: Investigation of Student Understanding". American Journal of Physic. 60, (11), 994-1003 
McKagan, et al (2008). "Developing and Researching PhET Simulation for Teaching Quantum Mechanics". Physics Education Technology Journal.www.colorado.edu/istem/pdfs/QMsims.pdf [19 Oktober 2012]

Richards, D. S (2010). A Case Study of Students' Conceptions On Electromagnetic Induction While Viewing A series of Video, Animations, and Interactive Simulations. Disertasi Doktor pada The Graduate School College of Education The Pennsylvania State University: tidak diterbitkan

Sugiyono. (2009).Statistika untuk Penelitian. Bandung: Alfabeta

Suparno, P (2005). Miskonsepsi dan Perubahan Konsep Pendidikan Fisika. Jakarta: Grasindo

Suhandi, A. dkk. (2008). Efektivitas Penggunaan Media Simulasi Virtual Pada Pendekatan Pembelajaran Konseptual Interaktif Dalam Meningkatkan Pemhaman Konsep dan Meminimalkan Miskonsepsi. Laporan Penelitian Hibah Kompetitif UPI. Bandung: FMIPA UPI

Tarakegn, G. (2009). "Can Computer Simulations Substitute Real Laboratory Apparatus?" Latin American Journal of Physics Education. 3, (3), 506517

Wenning, C.J. (2008). "Dealing More Effectively With Alternative Conceptions In Science". Journal of Physics Teacher Education Online. 5, (1), 11-19

Zacharia, Z.C danConstantinou, C. P. (2008)." Comparing the Influence of Physical and Virtual Manipulatives in the Context of The Physics by Inquiry Curriculum: The Case of Undergraduate students' Conceptual Understanding of Heat and Temperature". American Journal of Physic. 76, (4\&5), 425-430 